Word count: 8.057

\title{
Beyond Rote Learning in Organic Chemistry: The Infusion and Impact of Argumentation in Tertiary Education
}

\author{
Aybuke Pabuccu $^{* a} \&$ Sibel Erduran ${ }^{\mathrm{b}}$ \\ ${ }^{a}$ Department of Secondary Science and Mathematics Education, Faculty \\ of Education, Abant Izzet Baysal University, Turkey, +90 374254 1000, \\ aybuke@ibu.edu.tr; ${ }^{b}$ Department of Education, University of Oxford, \\ United Kingdom; National Taiwan Normal University, Taiwan; \\ University of Limerick, Ireland., +44-(0)1865-274019, \\ sibel.erduran@education.ox.ac.uk
}

*Corresponding author: Secondary Science and Mathematics Education, Abant Izzet Baysal University, Bolu 14280, Turkey, aybuke@ibu.edu.tr

\section{Notes on Contributor}

Aybuke Pabuccu is an Assistant Professor of Secondary Science and Mathematics Education at the Abant Izzet Baysal University of Turkey.

Sibel Erduran is a Professor of Science Education at University of Oxford, UK; Distinguished Visiting Chair Professor at National Taiwan Normal University, Taiwan; and Adjunct Professor at University of Limerick, Ireland. 


\title{
Beyond Rote Learning in Organic Chemistry: The Infusion and Impact of Argumentation in Tertiary Education
}

\begin{abstract}
There exists an unconscious bias among students that learning organic chemistry topics requires rote learning. In this paper, we tried to address this bias through an organic chemistry activity designed to promote argumentation. We present a study that investigated how students engage in an argumentation activity about conformational analysis of butane. Analysis of the student outcomes concentrated on (a) students' understanding of conformations of alkanes (b) the nature of the students' discourse; (c) the quality of students' argumentation; and (d) students' spatial ability. Various measures were used to trace (a) conceptual understanding through students' answers in the writing frames, (b) the nature of the students' discourse using two different codes, (c) the quality of student argumentation by counting the number of episodes with higher-level argumentation, and (d) students' spatial ability by Spatial Ability Test. The results led us to conclude that if the proper conditions were set, students could argue about the conformations of alkanes. Moreover, our data showed that high performing groups had multiple rebuttals in their argumentation and low performing groups had problems in evaluating the credibility of evidence. Furthermore, we observed that spatial abilities play an important role in students' engagement in higher-level argumentation. The results of the study help understanding of how to further enhance students' conceptual understanding in organic chemistry, engagement in argumentation, and enhancement of spatial ability regarding various organic chemistry concepts.
\end{abstract}

Keywords: Argumentation; Chemistry Education; Higher Education, Organic Chemistry 


\section{Introduction}

Contemporary perspectives in science education research advocate that science is not simply the accumulation of facts. Science requires the construction of theories and models that provide explanations for how the world may be. Scientific theories and models are open to challenge and refutation (e.g. Popper, 1959). Furthermore, science often progresses through dispute, conflict and argumentation rather than through general agreement (e.g. Kuhn, 1962/1970). Scientists construct a whole range of arguments including the validity of knowledge claims.

Despite such observations, the majority of school science still heavily relies on the outcomes of scientific inquiry rather than the processes of knowledge construction. The result is that school science instruction is dominated by 'facts' about the world. Although considerable research has been done within science education related to the inclusion of strategies such as argumentation in teaching and learning (Erduran \& Pabuccu, 2015; Erduran \& Jimenez-Aleixandre, 2007; Jimenez-Aleixandre, Bugallo, \& Duschl, 2000; Kelly \& Takao, 2002; Zohar \& Nemet, 2002), the use of argumentation in organic chemistry education is rather scarce (e.g. Christian \& Talanquer, 2012).

Organic chemistry in higher education has developed a reputation for being a "killer course" with attrition rates at some universities ranging as high as $30-50 \%$ (Grove, Hershberger, \& Bretz, 2008). Indeed, organic chemistry has historically been considered difficult (Bradley, Ulrich, Jones, \& Jones, 2002) and the reasons for student failures in organic chemistry are varied. One of the major problems with college students in learning organic chemistry is that these students strongly rely on a memorisationoriented approach to learning (Duffy, 2006; Grove \& Bretz, 2010). Moreover, it is well acknowledged in the literature that organic chemistry is a heavily spatial domain (Olimpo, Kumi, Wroblewskic, \& Dixon, 2015). Thus, spatial abilities play an important role in students' performance at organic chemistry (Harle $\&$ Towns, 2011). For instance, Pribyl and Bodner (1987) observed organic chemistry students with high spatial ability had greater success in organic problem solving.

In this paper, we present a study that utilized argumentation as a strategy to improve teaching and learning of organic chemistry. We 
have designed tasks that integrate argumentation in organic chemistry topics and investigated the relationships between preservice teachers' conceptual understanding, spatial ability and their engagement in the argumentation process by using the organic chemistry activity. The activity is part of a set of activities developed by Erduran and Pabuccu (2012) to promote argumentation in chemistry education through use of stories.

\section{Argumentation in Organic Chemistry Education at Tertiary Level}

The number of argumentation studies at university-level organic chemistry is limited (e.g. Christian \& Talanquer, 2012). For instance, De Arellano and Towns (2014) designed a study to investigate students' understanding of alkyl halide reactions in an undergraduate organic chemistry course. They interviewed twentytwo undergraduate students, ranging from their second to fourth year of study. The researchers used a think-aloud protocol with a set of questions dealing with reactions and mechanisms of alkyl halide molecules. They used Toulmin's model of argumentation to analyze the interviews. The researchers found that the gaps in understanding and incorrect warrants lead students to make mistakes when answering organic chemistry questions. Erduran and Pabuccu (2015) used an organic chemistry activity about conformations of alkanes for engaging university students in the argumentation process. The participants in this activity were 46 second year pre-service science teachers taking an organic chemistry class. For assessing the quality of argumentation, they focused on the rebuttals in the transcripts. According to Toulmin, rebuttals could be defined as the exceptional circumstances under which the claim would not be true (Erduran, Simon, \& Osborne, 2004). Although Erduran and Pabuccu (2015) found 39 rebuttals in the transcripts, many rebuttals occurred because the students did not understand the different spatial arrangements that a molecule can adopt.

Previous research has provided a broad view of the nature of students' understanding and the various factors that influence undergraduate and graduate students' success in organic chemistry (Graulich, 2015). For example, researchers have observed that 
students especially have remarkable difficulties in the abstraction of 3D information from 2D discipline-specific diagrams (Kumi, Olimpo, Bartlett, \& Dixon, 2013). Bodner and Domin (2000) suggested the two-dimensional (2D) diagrams are the most prevalent form of representation in chemistry. Thus, numerous research studies have focused on students' understanding of 2D diagrams (e.g. Kumi et al., 2013; Olimpo et al., 2015). The use of concrete and virtual models have been found to be helpful in improving students' understanding of 2D representations (Olimpo et al., 2015). However, such models are not always readily available (Kumi et al., 2013). Furthermore, simply viewing a 3D computer model may not be sufficient to improve students' understanding of 2D representations because many students may not understand what they are seeing (Springer, 2014) and they had problems in correctly interpreting them (Clauss \& Nelsen, 2009). Olimpo et al. (2015) suggested providing examples of molecules depicted in various conformations and opportunities to practice working with each of these representations of a molecule to help students who exhibit difficulty in understanding, manipulating, and translating between various representational forms.

In this study, we developed an organic chemistry activity about conformational analysis of butane because conformational analysis is a key topic in the organic chemistry curriculum and this topic requires understanding of 2D diagrams (e.g. the Dash-Wedge diagram, and the Newman projection, and the Fischer projection). In other words, it is a topic that has broad applications in organic chemistry and is not limited to butane. If students could not understand 2D diagrams, it could be more difficult for them to deal with more complex issues such as chirality (Pellegrinet \& Mata, 2005). In introductory organic chemistry, students learn how conformations affect the energy of a molecule (Barrows \& Eberlein, 2005). In most textbooks, the Newman projection is used in combination with graphs to illustrate a molecule's energetic changes due to gauche and anti-substituent relationships (Kumi et al., 2013). We also used such graphs in our activity to illustrate the potential energy relationships among the various conformations of butane.

Although conformations of the compounds are commonly shown by Newman projections, students and many professional chemists have difficulties with their use (Bodner \& Domin, 2000). 
For instance, Bodner and Domin (2000) observed that most students are more familiar with line structures of molecules than with Newman projections. Thus, in our activity, we encouraged students to think critically about the meaning and implications of Newman projections.

A Newman projection is used to identify spatial relationships between various substituents on adjacent carbons (Newman, 1955). Thus, in addition to sufficient content knowledge (e.g., understand the factors that increase potential energy of conformers), spatial ability is also important to accomplish our task. Spatial ability is important for students' understanding of organic chemical concepts like SN2 reactions, chirality, stereochemistry, and the different methods of representing molecules (Abraham, Varghese, \& Tang, 2010).

The present study is important because it contributes to the relatively limited literature on argumentation studies in universitylevel organic chemistry. The implicit goal of the paper is to encourage researchers and teachers to use argumentation activities in teaching organic chemistry topics and so weaning students away from rote learning. Moreover, the activity in this paper is about organic chemistry topics that required the engagement of spatial abilities (Harle \& Towns, 2011). Thus, there is also a unique contribution to the literature with regards to the role of spatial ability in pre-service teachers' conceptual understanding of organic chemistry topics and pre-service teachers' engagement in the argumentation process. Specifically, the following questions guided the research:

1. What is pre-service teachers' understanding of the conformational analysis of butane?

2. What is the nature of the pre-service teachers' discourse when they are immersed in an organic chemistry activity designed to promote argumentation?

3. What is the quality of pre-service teachers' argumentation in the context of an organic chemistry activity?

4. How does pre-service teachers' spatial ability relate to their understanding of organic chemistry concepts and their engagement in argumentation?

Collectively, these questions address how pre-service teachers's engagement can be promoted in organic chemistry in general and in 
argumentation about conformational analysis of butane in particular.

\section{Methods}

\section{Participants}

The participants were second year pre-service science teachers between the ages of 19-21 enrolled in a semester long organic chemistry course at a public university in Turkey. The full degree programme lasts for 4 years. Eighty-nine pre-service teachers participated in an activity from two classes. Twenty-one percent of the pre-service teachers were male and $79 \%$ were female. The organic chemistry course was taught by the first author of this paper. Pre-service teachers had taken general chemistry I and II during their first year and had not previously received formal training in argumentation.

\section{Classroom intervention}

An organic chemistry activity was designed taking into account some argumentation strategies. The aim of the activity was to improve pre-service teachers' understanding of the conformational analysis of butane. Conformations of alkanes and cycloalkanes had previously been taught and the pre-service teachers had been exposed to VSEPR theory, classification of isomers, different methods of representing molecules (e.g. Newman projections, wedge-and-dash drawings), and various types of strains in different conformations of a molecule.

For the activity, pre-service teachers were asked to get into groups of 3-5. The 22 groups in the study were either all female or all male. Each group was provided one written frame, which included a discussion question, a graph, evidence statements and a table (Appendix I). Pre-service teachers had to work together to produce one written answer in the frame, which involved (a) placing missing formulas on a graph, and (b) constructing their best explanation to support their choices. The graph illustrated the potential energy relationships among the various conformations of butane. Two Newman projection formulas were correctly placed on the graph (at points $\mathrm{E}$ and $\mathrm{F}$ ), while four others were missing at points A-D. Pre-service teachers were given 5 possible formulas 
and had to choose which 4 to correctly place on the graph at these points. One formula, which was isobutane, was included as a distractor and could be labeled as "none" to indicate not having a corresponding place on the graph.

For producing written justifications of each match, we provided evidence statements related to types of strains and types of isomers (Appendix I) which pre-service teachers were required to first analyze and then apply to their explanations. Each formula might require a different number of evidence statements. Some of the evidence statements were distractors, containing accurate information, yet nothing useful or relevant to answer the questions. During the activity, audiotape recorders were used to record discussions. The data analysis was done using these audiorecordings so the data were limited to those who could be clearly heard on the recordings. The pre-service teachers completed the activity in two 50-minute lessons. They could only use materials in the written frame during the activity.

\section{Data Analysis}

Data were collected through writing frames, tape recordings of the group discussions and the spatial ability tests. The following paragraphs describe each of the analyses in more detail in relation to the research questions.

RQ1 Investigating pre-service teachers' understanding of the conformational analysis of butane

aWe investigated if pre-service teachers made correct predictions about the placement of five Newman projection formulas on the graph by scoring answers. Each correct match was scored as +1 point. The main aim of the activity was to motivate pre-service teachers to find accurate and plausible evidence and then use such evidence in their explanations. Thus, an additional +1 point was given for each accurate and plausible evidence and -1 point for each wrong and irrelevant one. Incorrect matching of formulae were given a 0 score and their corresponding explanations were not analyzed or scored. The following is an example of one group's explanation. 
It (Formula I) has no strain because it is staggered and atoms were not too close to each other. Also, it has tetrahedral shape and point $\mathrm{D}$ has the lowest potential energy (on the graph).

We assigned a score of +5 points as follows:

Correct Placement $(+1 \mathrm{pt})$

The evidence used in the reasoning:

- Formula I is staggered $(+1)$

- Atoms were not too close to each other $(+1)$

- It has tetrahedral shape $(+1)$

- Point D has the lowest potential energy (on the graph) $(+1 \mathrm{pt}$.

Here is another group's explanation for Formula II and final calculation of a +1 score:

Two methyl groups close to each other so it has van der Waals strain. Also, the angle is $60^{\circ}$ degrees so there should be an angle strain.

\section{Correct Placement $(+1 \mathrm{pt})$}

Evidence used in the reasoning:

- Two methyl groups close to each other $(+1)$

- The angle is $60^{\circ}$ degrees $(-1)$

RQ2 Characterizing the nature of the pre-service teachers' discourse

To determine the nature of the pre-service teachers' discourse, we classified their contribution through two pre-determined codes: (a) "Doing school" and (b) "Chemistry content" (see Figure 1). These codes were developed and used in other studies (JimenezAleixandre et al., 2000; Pabuccu \& Erduran, 2016). Descriptions and examples of discourse for each code are provided below. Transcriptions have been translated into English by one of the authors of the paper. Two authors coded the transcripts independently and then compared their codes. The inter-rater reliability for the coding was $85 \%$ (Cohen's kappa $=0.88)$ and the 
remaining $15 \%$ of variance between the coders was resolved through discussion."

Doing school. The code refers to this concept as the actions and procedural displays, which constitute the routines and rituals in a school setting (Furberg \& Ludvigsen, 2008). Procedural displays could be defined, as the social habits of life in classrooms that are not necessarily initiated through questions and that often may not bear explicit purpose to students. Jimenez-Aleixandre et al. (2000) reported the conversational dynamics in the form of argumentation patterns and epistemic operations students' employ while solving a problem in the classroom. "Doing school" and "doing science" became the frame of reference when they analyzed student discourse within discussion groups. An example of "doing school" code is provided at Table 1.

Figure 1. Concept map for the codes of the study

Chemistry content. Pabuccu and Erduran (2016) developed this code to investigate how often students accept or oppose claims about the chemistry content proposed by other group members. Also, they classified Chemistry content code into two subcategories as 'Accept' and 'Opposition' (see Figure 1). Accept was used when pre-service teachers in the groups agree with the first pre-service teachers' claim about the chemistry content outright or reinforce the claim with additional data or warrants. For Opposition, they searched the groups' transcripts to identify episodes of opposition. Examples of these codes are given in Table 1.

Table 1. Examples of the codes of the study

\section{RQ3 Assessing the quality of argumentation}

To assess the quality of pre-service teachers' argumentation, we used an analytical framework that was developed by Erduran et al. (2004), which has been widely used (e.g. Kulatunga, Moog, \& Lewis, 2013; Simon \& Johnson, 2008). This framework presents a hierarchy of increasing quality of rebuttals applied to a set of five levels of argumentation. Because Erduran et al. (2004) accepted the presence of a rebuttal as a significant indicator of quality of argumentation, they assessed the nature of the opposition in terms 
of the strength of the rebuttals offered. For instance, when there was opposition between pre-service teachers but the opposition consisted of only counter-claims that were unrelated, they considered the transaction as low-level argumentation. However, if the argumentation had a rebuttal, which was in direct reference to data, warrants, or backings offered by the opponent, they considered it as higher-level argumentation. They also differentiated three levels of higher-level argumentation: arguments with a weak or incomplete rebuttal; arguments with a clear rebuttal; and arguments with multiple rebuttals. In our study, for the quality of the argumentation, we just focused on the higher-level argumentation that we extracted from the cases of 'Opposition' as previously described.

The following excerpt is an example of low-level argumentation. The episode only contains an oppositional response that simply rejects the proposal with a counter-claim.

S1: (the molecule represented by) Formula III is eclipsed.

S2: No. It is staggered.

S1: but..it is...

The following excerpt is an example of one higher-level argumentation. Here, there is a rebuttal, which directly opposes the componetns of the initial claim. Also, at the end of the discussion, $\mathrm{S} 1$ changed her mind and the pre-service teachers figured out that Formula V does not having a corresponding place on the graph.

S1: Formula V should be placed at Place B.

S2: No, No. Look here. Two methyl groups attached to a common carbon so it is not n-butane.

S3: Isobutane.

S1: Actually, it looks like different from the others. Yes, I see now.

S4: So, there is no place for it on the graph.

Here is another higher-level argumentation, which presents an extended argument with more than one rebuttal.

S1: Also, there is an angle strain here (Formula II).

S2: No there is not. 
$\mathrm{S} 1$ : But there is....look at the angle between methyl groups, $60^{\circ}$ degree.

S2: So, it has van der Waals strain.

S1: Ok but it should have an angle strain too.

S3: Could you define the angle strain please?

S2: Angle strain only occurs when bond angle is smaller than $109.5^{0}$ degrees. So, there is no angle strain here.

S1: It occurs when atoms are close to each other.

S3: The evidence statement says, "Destabilization due to distortion of a bond angle from its optimum value... in the case of alkanes the ideal value is $109.5^{\circ}$."

S1: Look at the angle between the methyl groups. It is $60^{\circ}$ so it is smaller than $109.5^{\circ}$. Right?

S2: Yes, it is $60^{\circ}$..so there is van der Waals strain because the groups are too close to each other..... but still there is no angle strain.

S4: Why not?

S2: Look the groups here. They are separated equally from each other like these [she uses pencils to show the groups]... like the corners of a tetrahedron... with $109.5^{\circ}$ bond angle because it is butane. If it was cyclobutane or cyclopropane, for example, it should have an angle strain.

S1: Thus, no angle strain here.

\section{RQ4. Examination of pre-service teachers' spatial ability}

The Spatial Ability Test (SAT) developed by Ekstrom, French, and Harman (1976) was utilized to score the quality of pre-service teachers' spatial ability. SAT is a paper pencil test, composed of sub-tests to measure pre-service teachers' spatial orientation ability (SOA) and spatial visualization ability (SVA). We used Card Rotation Test (CRT) and Cube Comparison Test (CCT) to examine pre-service teachers' spatial orientation ability; and Paper Folding Test (PFT) and Surface Development Test (SDT) to examine preservice teachers' visualization ability (SVA).

CRT measures the ability to see differences between shapes and consists of true-false items. Each choice of 'true' is one point. CCT is also composed of true-false items, but relates to whether the given cubes with various markings (i.e. letters, shapes, etc.) are the same. Each question includes 8 items and one point is given to each true item. PFT requires participants to answer multiple-choice 
items based on accurately visualizing folding and unfolding pieces of paper. In the evaluation of the test, each choice of 'true' is one point. SDT demands participants to visualize various geometric shapes from folded paper. There are five answers to match in each question and one point is given to each 'true' answer.

The number of questions and reliability coefficients (KR-21) for each test is given in Table 2. We calculated scores of the SAT by the summation of the subtests of SAT.

Table 2. Reliability coefficients, number of questions $\&$ durations

\section{Results \& Discussion}

In this section, the results of the study are presented in terms of the research questions. Table 3 and Table 4 present the total scores of the groups' written frames. To examine the reasons behind the tremendous differences between the scores of high performing and low performing groups, we compared the research questions of the study only for these four groups.

RQ1 What is pre-service teachers' understanding of the conformational analysis of butane?

The total scores of each group's written frames were calculated (see Table 3 and 4). Then, the four groups were chosen from a larger subset of 22 groups by using a two-step process. First, all groups were ordered from high to low based on their scores from the written frames ( 21 points possible, Maximum $=17$, Minimum $=$ 0 , Mean $=5.32$, Standard Deviation $=4.42$ ). Then, two groups from each classroom were chosen from the high and low succeeding groups. At this stage, the authors reviewed the audio recordings multiple times to ensure these cases weren't exceptions or outliers.

Table 3. Written report analysis for the groups of first classroom

Table 4. Written report analysis for the groups of second classroom

To answer the questions appropriately, pre-service teachers should (a) make correct predictions about the placement of five Newman projection formulas on the graph and then (b) construct 
their best explanation to support their predictions. For producing written justifications of each placement, we provided evidence statements related to types of strains and types of isomers (Appendix I). The task was also intended to motivate pre-service teachers by engaging in evidence statements written on cards. They would have to find accurate and plausible evidence, analyze the evidence statements and then use it in their own explanations.

In the activity, only $23 \%$ of the groups correctly placed all missing formulas on the graph. The percentages of the correct placement for each formula were as follows: Formula I (73\%); Formula II (52\%); Formula III (52\%), Formula IV (61\%) and Formula V (39\%). It seems that the pre-service teachers had the most difficulty in placing Formula $\mathrm{V}$ on the graph. A potential reason for this is that Formula $\mathrm{V}$ was included as a distractor and should be labeled as "none" to indicate not having a corresponding place on the graph. Thus, to label Formula V as none, the preservice teachers needed to comprehend the difference between stereoisomers and structural isomers. Here it seems that providing rote information (three evidence statements in Appendix I) for both stereoisomers and structural isomers to the pre-service teachers did not guarantee that they could use this information properly. Furthermore, they should understand how Newman projection formulas are used to illustrate conformational isomers. They could see that two methyl groups attached to a common carbon at Formula $\mathrm{V}$ so it is not n-butane.

Our data also indicated that making a match on the graph did not always come along with plausible evidence used in the descriptions provided by participants. In total, we found 12 inappropriate uses of evidence in groups' explanations to justify their correct placements (see Table 5). Indeed, the main difference between the scores of high and low performing groups basically depends on the pre-service teachers' ability to evaluate the credibility of evidence. For instance, Group 3 (low performing group) made three correct predictions and Group 11 (high performing group) made five correct predictions during the activity (see Table 3 ). However, the scores for these two groups are respectively, 1 and 15. The main differences between the scores were based on providing enough and plausible evidence in groups' justifications. For instance, both Group 3 and Group 11 pre-service teachers correctly placed Formula II on the graph. 
However, to justify their placement, Group 3 used an inappropriate evidence that stated that the bond angles in Formula II are lower than $109.5^{\circ}$. Thus, they used the evidence statements for an angle strain (see Appendix I) and decided that Formula II should have an angle strain. Group 3 pre-service teachers had difficulty in determining angle strain; even the definition for the angle strain was given in the written frame. That was mainly because they confused bond angle with dihedral angle. This misconception could result because the pre-service teachers memorized the definition of the bond angle and dihedral angle. Thus, they had superficial knowledge about angle strain and van der Waals strain. Moreover, probably Group 3 pre-service teachers could not see that all conformations of butane have tetrahedral shape so there is no distortion of a bond angle from its optimum value for the conformations of butane. In contrast to Group 3, Group 11 pre-service teachers used correct evidence to justify their predictions that was the conformations of butane should have tetrahedral shape with bond angle of $109.5^{0}$.

Table 5. Frequency of inappropriate evidence for different topics

RQ2. What is the nature of the pre-service teachers' discourse when they are immersed in organic chemistry activity designed to promote argumentation?

The nature of the pre-service teachers' discourse was analyzed by the frequency within each group of initiating various codes. If a stretch of a discourse remained within one code, that entire stretch was counted only once for that code, even if there were multiple turns. As soon as the discourse switched to a new code, the ensuing new segment was counted as one for that new code. Besides, all groups appeared at ease during their interactions and were highly engaged in the activity. Table 6 shows the percentages of two codes ("Doing school" and "Chemistry content") out of the total number of codes for four selected groups. In terms of the data at Table 6, the percentages of "Doing school" codes for the groups were similar, except Group 11 (\%36). Thus, we can state that both high and low performing groups spent remarkable time focusing on doing the activity ("Doing school"). Other studies have reported similar results with student dialogues during argumentation 
predominantly bearing references to school culture (e.g. JimenezAleixandre et al., 2000; Pabuccu \& Erduran, 2016).

Table 6. Percentages of the codes of the study

According to Table 6, Group 11 had the highest percentage (64\%) for "Chemistry content" code so we can say that Group 11 pre-service teachers were more eager to talk about the conformation analysis of butane than the other three groups. Then, we concentrated on how the participants argued with each other during the activity related to two sub-categories of "Chemistry content" code; "Accept" and "Opposition". For "Opposition", we searched the transcripts to find the episodes when pre-service teachers contradicted each other, and for "Accept", we searched for the episodes when pre-service teachers either supported the first speaker's claim using other data or warrants or when they simply agreed with the claim outright. Figure 2 presents for "Accept" and "Opposition" codes for four groups. As it is seen in the Figure 2, all four groups had higher percentages for "Accept" code than that of "Opposition"' code.

It means that pre-service teachers usually tend to accept the first claim instead of opposing it, during the activity. This is probably because they could are of expressing their opinions (Nussbaum \& Jacobson, 2004) or pretend to agree most of time due to social or other reasons (Kim, 2009). Moreover, the pre-service teachers were not used to opposing any unjustified claims made by their teacher or classmates in the science classroom.

Figure 2. Percentage of the "Accept" and "Opposition" codes

RQ3 What is the quality of pre-service teachers' argumentation in the context of organic chemistry?

Table 7 illustrates the percentage of oppositional episodes with low-level and higher-level argumentation. For instance, Table 7 presents that only $25 \%$ of Group 3 argumentation was labeled as higher-level argumentation with a weak rebuttal. Indeed, low performing groups infrequently provided rebuttals as part of their arguments.

Table 7. Percentages of low-level \& higher-level argumentation 
As seen in Table 7, the highest percentages for higher-level argumentation were observed for the high performing groups, Group $11(86 \%)$ and Group $13(83 \%)$. Also, Table 7 presents the percentages for higher-level argumentation into three sublevels: arguments with a weak rebuttal, arguments with a clear rebuttal and arguments with multiple rebuttals. For example, $14 \%$ of the higherlevel argumentation of Group 11 had a weak rebuttal, 29\% had a clear rebuttal and $43 \%$ had multiple rebuttals in its' argumentations. Table 7 shows that low performing groups could not produce multiple rebuttals. We chose the presence of a rebuttal as a significant indicator of the quality of argumentation in line with previous studies (Erduran et al.,2004; Erduran \& Pabuccu, 2015). Pre-service teachers need to fully engage with their and others' evidence and justification to be able to refute the others' claims with evidence. Thus, we assumed that high performing groups in terms of rebuttals were more engaged in the argumentation process than the low performing ones.

In total, there were 14 rebuttals in the transcripts of selected groups for this activity. These rebuttals were about: the angle strains (3 instances); Newman projection formulas (3 instances); eclipsed/staggered conformations (5 instances); and the structural isomer of n-butane (3 instances). During the higher-level argumentation, the pre-service teachers interact and help each other to understand (a) how Newman projection formulas are used to illustrate conformational isomer, (b) when eclipsed or staggered conformations occur, (c) why the conformations of butane should have tetrahedral shape with bond angle of $109.5^{\circ}$ and (d) the difference between stereoisomers and structural isomers. We observed that all the higher-level argumentation ended with arriving at a consensus with the correct answer.

RQ4 How does pre-service teachers' spatial ability relate to their conceptual understanding of organic chemistry concepts and their engagement in the argumentation process?

At the first lesson of the organic chemistry course, 89 preservice teachers utilized the sub-tests of the SAT. The score of the SAT is obtained by the summation of these tests. Then, we compared SAT scores of low performing and high performing groups. Table 8 presents the means, maximum and minimum 
values of SAT scores with respect to the low performing and high performing groups of the study. Pre-service teachers SAT scores indicated that there was no significant difference between these four groups and so the pre-service teachers had roughly similar spatial ability. This result is interesting because not only in terms of subject knowledge but also in terms of the spatial ability being important to accomplish the task. The reason for this finding could be that conceptual understanding was monitored through group responses to the writing frames (i.e. pre-service teachers had to work together to produce one written answer in the frame). Thus, how pre-service teachers engaged in the argumentation process was effective for group score from the written frames. For instance, when we looked at groups' argumentation, we found that preservice teachers resolved all inaccurate claims by engaging in higher-level argumentation. Besides, many rebuttals occurred because the pre-service teachers did not understand the different spatial arrangements that a molecule can adopt. Thus, we assumed that spatial abilities play an important role to promote pre-service teachers' argumentation.

Table 8. Means, Maximum and Minimum Values of SAT scores

\section{Conclusions and Discussion}

It is widely held that designing learning environments to engage pre-service teachers in evidence-based reasoning in relation to scientific issues is one of the goals of science education. Often such issues emerge in complex situations, for instance, that demand the ability to evaluate the credibility of evidence using a set of criteria such as accuracy and plausibility of the evidence (Erduran \& Pabuccu, 2012). Our approach in the design of an organic chemistry activity was to motivate pre-service teachers to consider and evaluate evidence and to generate justifications for their positions. More specifically, here we reported a study that focused on the design and evaluation of a task that supports the use of argumentation in an organic chemistry context.

In the study reported in this paper, the main difference between the scores of high and low performing groups based on pre-service 
teachers' ability to evaluate the credibility of evidence. Thus, we suggest that evaluating evidence is an important ability for preservice teachers. Moreover, we provided evidence statements related to types of strains and types of isomers (see Appendix I). In this way, we aimed to investigate what would happen if pre-service teachers were provided with some rote information and then asked to analyze and apply this information. Our data indicated that providing rote information to the pre-service teachers did not guarantee that they could use them properly. Indeed, we observed that pre-service teachers usually had difficulty in understanding (a) how Newman projection formulas are used to illustrate conformational isomers; (b) how some factors increase potential energy of conformers; and (c) how structural isomers differ from stereoisomers.

Another significant finding is that high performing groups had multiple rebuttals in their argumentation. Many studies in the literature have reported that pre-service teachers often supported their claims with data and warrants but rarely offered rebuttals (Pabuccu \& Erduran, 2016; Simon, Osborne, \& Erduran, 2003). Argumentation with multiple rebuttals was rarely observed in students' discussions even when students were given instruction about the argumentation process (Erduran et al., 2004). The fact that our organic chemistry activity managed to engage pre-service teachers to make multiple rebuttals is encouraging. Moreover, our data indicated that higher-level argumentation let pre-service teachers interact with each other and all of them ended up with changing at least one student's mind (or misconception) and help that student understand the organic chemistry topic they were discussing. The argumentation strategies embedded in the task encourage peer learning that extended beyond argumentation and had influence on conceptual understanding.

Since it was challenging for pre-service teachers to understand varying spatial arrangements and graphic representations of the molecules, it was not surprising that they devoted much time discussing them and often used rebuttals. Indeed, most of the time they tried to understand the spatial arrangements of the molecules together. Thus, we assumed that pre-service teachers' spatial ability was an effective factor in promoting their high-level argumentation in organic chemistry. 
We did not find a significant difference between the groups' SAT scores so we assumed that both low and high performing preservice teachers had similar quality of spatial ability. However, the main differences between these two groups was that high performing groups had higher-level argumentation, which enabled the improvement of each other's understanding about the different spatial arrangements butane can adopt. Thus, during the higherlevel argumentation, we assumed pre-service teachers help each other to understand different spatial arrangements of atoms relative to rotations about bonds. Hence, even though there was no significant SAT score differences, engagement in the task facilitated conceptual understanding of the conformational analysis of butane through peer support and discussion.

Although in our previous studies, we observed some group members (e.g. high school students) trying to dominate the group discussion, in this study, we did not come across this situation. This could be due to the mature age of the pre-service teachers (19-21 years old) and more experiences with group discussions. The participants tried to answer the questions together. The collaborative spirit of the groups may help explain why the SAT scores were similar indicating a similar level of ability and skill.

There was no significant difference between the low performing and the high performing groups instead of spending time talking about how they should do the activity (Doing school). Moreover, many pre-service teachers were more willing to support each other, instead of opposing. Although we did not find any differences, we believe that if we can move the pre-service teachers away from the procedural displays in the activity (Doing school), they could spend more time to talk about organic chemistry topics (Chemistry content). For instance, Jiménez-Aleixandre and her colleagues (2000) defined "doing school" as a major obstacle to "talking science" in the science classes. Thus, if the influence of the school culture in the production of arguments diminishes, students could focus on providing scientific justifications for what they believe in instead of fulfilling the task of "writing why" (Jiménez-Aleixandre et.al., 2000). Moreover, the more time pre-service teachers spent discussing about science, the more chance of opposing each other. If pre-service teachers were encouraged to oppose the others' claims with evidence, they can produce more high-level argumentations. 
The activity we present in this paper is critical in providing preservice teachers with experiences in argumentation including substantiating claims and refuting others' claims with evidence. The engagement in such aspects of argumentation shifts the nature of the learners' experience of organic chemistry that is typically passive and based on rote learning. In this study, the participants already had been introduced to the organic chemistry content so the engagement in the argumentation task serve as a way to consolidate what they already learned and contribute to what they might have misunderstood. In future studies, the role of the content knowledge in relation to the argumentation process can be explored further. For example, we do not know if the organic chemistry concepts can be introduced afresh using the argumentation framework given that the learners are provided with the content knowledge in the task components. Allowing the learners, be it pre-service teachers or secondary students, to engage in the learning of the subject knowledge through argumentation could potentially prove fruitful particularly given the amount of peer learning that such carefully designed activities enable in group discussions. Overall the paper contributes to the research literature on argumentation in science education and paves the way for further investigations in how traditional content that is based heavily on memorization can be revitalized for more motivating, engaging and active learning.

\section{References}

Abraham, M., Varghese, V., \& Tang, H. (2010). Using molecular representations to aid student understanding of stereochemical concepts. Journal of Chemical Education, 87(12), 1425-1429. doi:10.1021/ed100497f

Barrows S.E., \& Eberlein T.H. (2005). Cis and trans isomerization in cyclic alkenes: a topic for discovery using the results of molecular modeling. Journal of Chemical Education. 82(9), 1334.

Bodner G., \& Domin D. (2000). Mental models: the role of representation in problem solving in chemistry. University Chemistry Education, 4(1), 24-30. 
Bradley A., Ulrich S. M., Jones M., Jones S. M. (2002). Teaching the sophomore organic course without a lecture. Are you crazy? Journal of Chemical Education. 79, 514-519. doi:10.1021/ed079p514

Christian K., \& Talanquer V. (2012). Content-related interactions in self-initiated study groups. International Journal of Science Education, 34, 2231-2255. doi:10.1080/09500693.2012.708064

Clauss, A. D., \& Nelsen, S. F. (2009). Integrating computational molecular modeling into the undergraduate organic chemistry curriculum. Journal of Chemical Education, 86(8), 955-958. doi:10.1021/ed086p955

De Arellano D. C. R., \& Towns M. (2014). Students understanding of alkyl halide reactions in undergraduate organic chemistry. Chemistry Education Research and Practice, 15, 501-515. doi:10.1039/C3RP00089C

Duffy, A. M. (2006). Students' ways of understanding aromaticity and electrophilic aromatic substitution reactions (Unpublished doctoral dissertation). University of California, San Diego.

Erduran, S., \& Pabuccu, A. (2015). This is a chapter. In Ingo Eilks and Avi Hofstein (Eds.), Relevant Chemistry Education - From Theory to Practice (pp. 143-161). Sense Publishers: Rotterdam.

Erduran, S., \& Pabuccu, A. (2012). Bonding Chemistry and Argument: Teaching and Learning Argumentation through Chemistry Stories, a booklet, Retrieved from http://www.bristol.ac.uk/education/news/2012/63.html

Erduran, S., \& Jimenez-Aleixandre, M. P. (Eds.) (2007). Argumentation in Science Education: Perspectives from Classroom-Based Research. Dordrecht: Springer. 285p

Erduran, S., Simon, S., \& Osborne, J. (2004). TAPping into argumentation: Developments in the application of Toulmin's argument pattern for studying science discourse. Science Education, 88, 915-933. doi:10.1002/sce.20012

Ekstrorn, R. B., French, J. W., \& Harman, H. H. (1976). Manual for kit of factor referenced cognitive tests. Princeton, NJ: Educational Testing Service.

Furberg, A., \& Ludvigsen, S. (2008). Students' meaning making of socio scientific issues in computer mediated settings: Exploring learning through interaction trajectories. International Journal of Science Education, 30(13), 1775-1799. doi:10.1080/09500690701543617 
Graulich, N. (2015). The tip of the iceberg in organic chemistry classes: how do students deal with the invisible? Chemistry Education Research and Practice, 16, 9-21. doi:10.1039/C4RP00165F

Grove N. P., \& Bretz S. L. (2010). Perry's scheme of intellectual and epistemological development as a framework for describing student difficulties in learning organic chemistry. Chemistry Education Research and Practice, 11, 207-211. doi:10.1039/C005469K

Grove N., Hershberger J., \& Bretz S. L. (2008). Impact of a spiral curriculum on student attrition and learning. Chemistry Education Research and Practice, 9, 157-162. doi:10.1039/B806232N

Harle M., \& Towns M. (2011). A Review of Spatial Ability Literature, Its Connection to Chemistry, and Implications for Instruction. Journal of Chemical Education, 88, 351-360. doi:10.1021/ed900003n

Jimenez-Aleixandre, MP, Bugallo, A, \& Duschl, R.A. (2000). "Doing the lesson" or "doing science"; argument in high school genetics. Science Education, 84(6), 757-792. doi: 10.1002/1098-237X(200011)84:6<757::AID-SCE5>3.0.CO;2-F

Kelly, G.J., \& Takao, A. (2002). Epistemic levels in argument: an analysis of university oceanography students' use of evidence in writing. Science Education, 86(3), 314-342. doi:10.1002/sce.10024

Kim, B. (2009). The effects of prompts-based argumentation scaffolds on peer-led interactive argumentation (Unpublished doctoral dissertation). University of Missouri, Columbia.Kuhn, T. (1962/1970). The structure of scientific revolutions $\left(2^{\text {nd }}\right.$ ed.). Chicago: University of Chicago Press.

Kulatunga, U., Moog, R.S., \& Lewis, J.E. (2013). Argumentation and Participation Patterns in General Chemistry Peer-Led Sessions. Journal of Research in Science Teaching, 50(10), 1207-1231. doi:10.1002/tea.21107

Kumi B. C., Olimpo J. T., Bartlett F., \& Dixon B. L. (2013). Evaluating the effectiveness of organic chemistry textbooks in promoting representational fluency and understanding of 2D-3D diagrammatic relationships. Chemistry Education Research and Practice, 14, 177-187. doi:10.1039/C3RP20166J 
Matthews, M. (2014). International handbook of research in history and philosophy for science and mathematics education. Dordrecht, The Netherlands: Springer.

Newman M., (1955). A notation for the study of certain stereochemical problems. Journal of Chemical Education, 32(7), 344.

Nussbaum, E. M., \& Jacobson, T. E. (2004, July). Reasons that students avoid intellectual arguments. Poster session presented at the annual meeting of the American Psychological Association, Honolulu, HI.

Olimpo, J.T., Kumi, B.C., Wroblewskic, R., Dixon B.L. (2015). Examining the relationship between 2D diagrammatic conventions and students' success on representational translation tasks in organic chemistry. Chemistry Education Research and Practice, 16, 143-153. doi:10.1039/C4RP00169A

Pabuccu, A., \& Erduran, S., (2016). Investigating students' engagement in epistemic and narrative practices of chemistry in the context of a story on gas behavior. Chemistry Education Research and Practice, 17, 523- 531. doi:10.1039/C6RP00011H

Pellegrinet, S. C., \& Mata E.G. (2005). A set of hands-on exercises on conformational analysis. Journal of Chemical Education, 82, $73-74$.

Popper, K. (1959). The logic of scientific discovery. Hutchinson, London.

Pribyl J.R., \& Bodner G.M. (1987). Spatial ability and its role in organic chemistry: a study of four organic courses. Journal of Research in Science Teaching, 24(3), 229-40.

Sampson, V., \& Clark, D. (2011). A comparison of the collaborative scientific argumentation practices in two high and two low performing groups. Research in Science Education, 41(1), 63-97. doi: 10.1007/s11165-009-9146-9

Simon, S., \& Johnson, S. (2008). Professional learning portfolios for argumentation in school science. International Journal of Science Education, 30(5), 669-688. doi:10.1080/09500690701854873

Simon, S., Osborne, J., \& Erduran, S. (2003). This is a chapter. In J. Wallace \& J. Loughran (Eds.), Leadership and professional development in science education: New possibilities for enhancing teacher learning (pp. 198-217). London \& New York: Routledge Falmer. 
Springer, M. T. (2014). Improving students' understanding of molecular structure through broad-based use of computer models in the undergraduate organic chemistry lecture, Journal of Chemical Education, 91, 1162-1168. doi:10.1021/ed400054a Zohar, A, \& Nemet, F. (2002). Fostering students' knowledge and argumentation skills through dilemmas in human genetics. Journal of Research in Science Teaching, 39(1), 35-62. doi:10.1002/tea.10008 


\section{APPENDIX I - The Written Frame (From Erduran \& Pabuccu, 2012)}

Question. The graph below shows the changes that arise from rotation about $\mathrm{C} 2-\mathrm{C} 3$ bond of butane. Here are the two Newman projection formulas for the conformations of butane. The other four Newman projection formulas for the conformations of butane at point $\mathrm{A}, \mathrm{B}, \mathrm{C}$ and $\mathrm{D}$ were erased on the following graph.

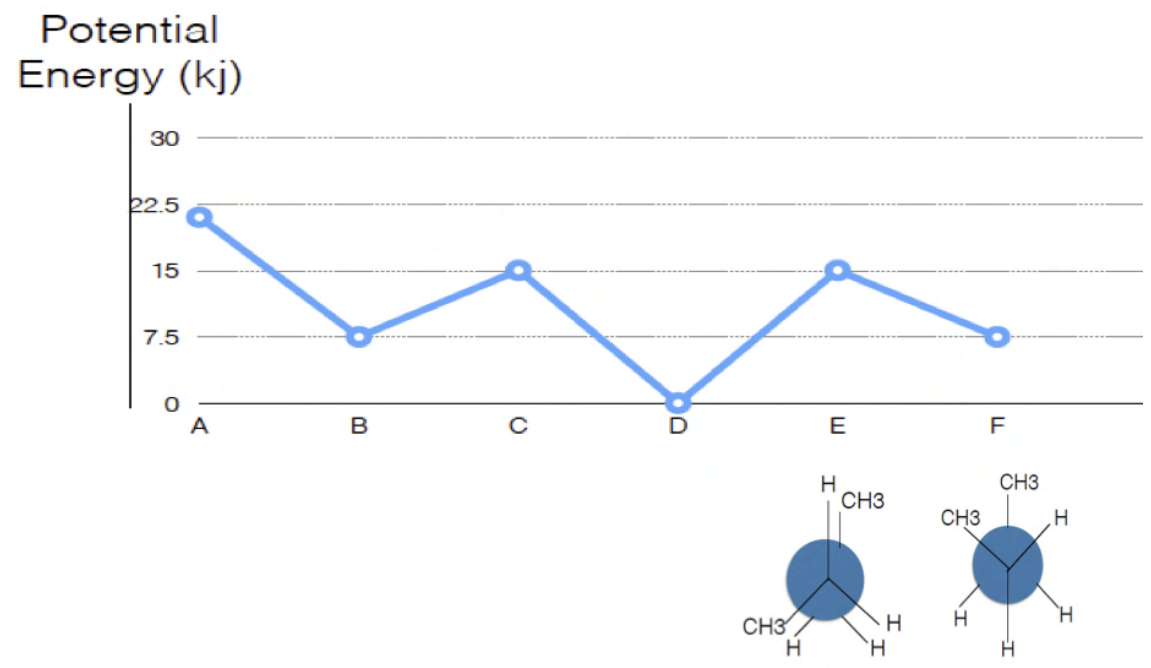

Five different Newman projection formulas are presented below. Look at them and try to estimate the erased Newman projection formulas on the graph (Figure 3). Complete the following table by constructing the best explanation for the question. You can use the following evidence statements to name the strain(s) at the formulas but you will need to specify why you selected the card(s) to be used in your explanation. You do not need to use all evidence statements and also you can use one card more than once.
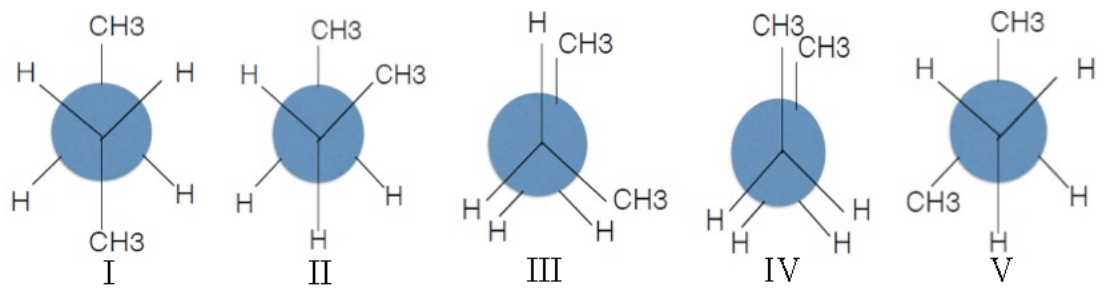


\section{Evidence Statements}

Torsional strain: Destabilization due to the repulsion between pairs of bonds caused by the electrostatic repulsion of the electrons in the bonds. Thus, it comes from eclipsed bonds on adjacent atoms.

Van der Waals strain: Destabilization due to the repulsion between the electron clouds of atoms or groups. This occurs when atoms or groups are too close to each other due to the electrostatic repulsion of the electrons.

Angle Strain: Destabilization due to distortion of a bond angle from its optimum value caused by the electrostatic repulsion of the electrons in the bonds; in the case of alkanes the ideal value is $109.5^{\circ}$.

In structural isomers, the atoms and functional groups are joined together in different ways.

In stereoisomers, the bond structure is the same, but the geometrical positioning of atoms and functional groups in space differs.

Isobutane is more energetically stable than n-butane.

\begin{tabular}{ccc}
\hline Formulas & Place $^{*}$ & Our explanations \\
\hline I & &
\end{tabular}

III

IV

V

${ }^{*} \mathrm{~A} / \mathrm{B} / \mathrm{C} / \mathrm{D} / \mathrm{None}$ 


\section{Tables With Captions}

Table 1. Examples of the codes of the study

\begin{tabular}{|l|c|}
\hline Classroom talk & Code \\
\hline S1: Let's share the evidence statements so each of us & \\
can take responsibility for her/his own cards. & \\
S2: Now, we should use them in our explanations & \\
S3: How many cards we should use for each & Doing \\
explanation? & School \\
S1: I think one is enough. & \\
S4: Ok. & Chemistry \\
\hline S1: Formula I looks like is the most stable one. & Content \\
S2: It seems so & Accept \\
S1:...so it should be placed at point D. & \\
S3: ...lowest potential energy & \\
S4: yes, it is staggered and molecules are far from each & \\
other, so a point D for it. & \\
\hline S1: There should be Van Der Waals Strain at Formula & Chemistry \\
II & Content \\
S2: No, it has not. & Opposition \\
S1: Of course it is. Methyl groups close to each other. & \\
S2: Ok. & \\
\hline
\end{tabular}

Table 2. Reliability coefficients, number of questions $\&$ durations

\begin{tabular}{lcccc}
\hline Ability & Tests & Reliability & Number of Questions & Duration \\
\hline SVA & PFT & 0.80 & 20 & 12 Minutes \\
\hline & SDT & 0.74 & 60 & 6 Minutes \\
\hline & & & & \\
\hline SOA & CRT & 0.81 & 160 & 6 Minutes \\
\hline & CCT & 0.79 & 42 & 6 Minutes \\
\hline
\end{tabular}


Table 3. Written report analysis for the groups of first classroom

\begin{tabular}{lccccccccccc}
\hline Groups & 1 & 2 & $\mathbf{3}$ & 4 & 5 & 6 & 7 & 8 & 9 & 10 & $\mathbf{1 1}$ \\
\hline Prediction & 3 & 2 & $\mathbf{3}$ & 3 & 3 & 2 & 2 & 3 & 3 & 3 & $\mathbf{5}$ \\
\hline Evidence & 2 & 1 & $\mathbf{0}$ & 1 & 4 & 1 & 3 & 2 & 3 & 3 & $\mathbf{1 0}$ \\
& -1 & - & $\mathbf{- 2}$ & -1 & -1 & -1 & & -1 & & -1 & \\
\hline Total & 4 & 3 & $\mathbf{1}$ & 3 & 6 & 2 & 5 & 4 & 6 & 5 & $\mathbf{1 5}$ \\
\hline
\end{tabular}

Table 4. Written report analysis for the groups of second classroom

\begin{tabular}{lccccccccccc}
\hline Groups & 12 & $\mathbf{1 3}$ & 14 & 15 & 16 & 17 & $\mathbf{1 8}$ & 19 & 20 & 21 & 22 \\
\hline Prediction & 1 & $\mathbf{5}$ & 3 & 0 & 1 & 5 & $\mathbf{0}$ & 5 & 3 & 3 & 5 \\
\hline Evidence & 0 & $\mathbf{1 2}$ & 3 & 0 & 1 & 4 & $\mathbf{0}$ & 2 & 4 & 3 & 7 \\
& & & & & & -2 & & -1 & -1 & & \\
\hline Total & 1 & $\mathbf{1 7}$ & 6 & 0 & 2 & 7 & $\mathbf{0}$ & 6 & 6 & 6 & 12 \\
\hline
\end{tabular}

Table 5. Frequency of inappropriate evidence for different topics

\begin{tabular}{lc}
\hline Topic & Number of evidence \\
\hline Angle Strain & 9 \\
\hline Eclipsed/Staggered & 2 \\
\hline Isomer & 1 \\
\hline
\end{tabular}

Table 6. Percentages of the codes of the study

\begin{tabular}{lllll}
\hline & Low & Performing & \multicolumn{2}{l}{ High Performing } \\
Codes/Groups & G3 & G18 & G11 & G13 \\
Doing school & 52 & 50 & 36 & 46 \\
Chemistry content & 48 & 50 & 64 & 54 \\
\hline
\end{tabular}


Table 7. Percentages of low-level \& higher-level argumentation

\begin{tabular}{lllll}
\hline & Low Performing & \multicolumn{2}{c}{ High Performing } \\
\hline Argumentation & G3 & G18 & G11 & G13 \\
\hline Higher-level & & & & \\
\hline - with multiple rebuttals & - & - & 43 & 17 \\
\hline - with a clear rebuttal & - & 25 & 29 & 33 \\
\hline - with a weak rebuttal & 25 & 25 & 14 & 33 \\
& & & & \\
\hline Low-level & 75 & 50 & 14 & 17 \\
\hline
\end{tabular}

Table 8. Means, Maximum \& Minimum Values of SAT scores

\begin{tabular}{lcccc}
\hline Groups & $\mathrm{n}$ & Min. & Max. & Mean \\
\hline Low Performing & 8 & 166 & 225 & 198.68 \\
\hline High Performing & 9 & 163 & 236 & 195.32 \\
\hline
\end{tabular}




\section{Figure captions}

Figure 1. Concept map for the codes of the study

Figure 2. Percentage of the "Accept" and "Opposition" codes 